Тишина Елена Валерьевна

аспирант Гуманитарного университета, преподаватель Екатеринбургского колледжа транспортного строительства

\section{АНАЛИЗ ОПЫТА ОЦЕНКИ КАЧЕСТВА СРЕДНЕГО ПРОФЕССИОНАЛЬНОГО ОБРАЗОВАНИЯ}

\section{Аннотация}

В современном научном дискурсе недостаточно четко обозначена методология оценки качества среднего профессионального образования. В статье сделана попытка обобщить имеющийся опыт и выявить господствующие тенденции. Методами изучения выступили вторичный анализ результатов социологических исследований, проведенных в разные годы (2009-2016 га.) в организациях системы СПО; дискурс-анализ текстов отчетов об итогах данных опросов. Результаты показали, что мониторина качества образования становится популярной формой оценки, но методология его проведения остается недостаточно комплексной, системной. Преобладают опросные методы, ключевым является понятие «удовлетворенность потребителей». Автор делает заключение, что методология и методика социологической оценки качества среднего профессионального образования нуждаются в обновлении.

\section{Ключевые слова:}

качество образования, система среднего профессионального образования, методология, оценка качества образования, процессы, результаты, субъекты образования.
Tishina Elena Valeryevna

PhD student, University of Humanities, Lecturer, Yekaterinburg College of Transport Construction

\section{ANALYSIS OF EXPERIENCE IN ASSESSING THE QUALITY OF SECONDARY VOCATIONAL EDUCATION}

Summary:

In modern scientific discourse, the methods for assessing the quality of secondary vocational education are not clearly defined. The paper attempts to summarize the available experience and identify prevailing trends in this regard. The research methods include the secondary analysis of the results of sociological research carried out in different years (2009-2016); discourse analysis of the reports on the results of these studies. The findings show that education quality monitoring is becoming a popular form of assessment. At the same time, evaluation methods remain insufficiently integrated, non-systematic. Poll methods prevail. The concept of customer satisfaction is the key one. The author concludes that the methods of sociological evaluation of the quality of secondary vocational education need to be updated.

Keywords: quality of education, secondary vocational education system, methods, education quality assessment, processes, results, actors of education.

Постановка проблемы. Социологическое изучение вопросов качества среднего профрессионального образования (далее - СПО) становится все более актуальным. Во-первых, это обусловлено возрастанием роли и значения данного вида образования в современном российском обществе. Во-вторых, следует говорить о преобладающей ориентации системы СПО на требования рынка труда и запросы работодателя. Трудоустройство выпускников является важнейшим критерием качества образования. В связи с этим методологические и методические аспекты социологической оценки качества СПО выступают объектом научной дискуссии. В статье мы сделали попытку обобщить имеющийся опыт оценки качества СПО и выявить некоторые тенденции в конструировании такой методики.

Обзор литературы. Анализ источников по данной теме позволяет заключить, что преждевременно говорить о господстве какой-либо устоявшейся методологической основы. В целом специфика СПО при оценке качества образования выделена недостаточно. Скорее она вписывается в общий контекст оценки качества образования. В данном случае можно установить несколько базовых подходов к оценке качества образования, они заключаются в следующем.

Первый подход может быть условно назван результатным, поскольку методика оценки качества образования базируется на определении конечных и промежуточных целей образования и сопоставлении их с реальной картиной. Чаще всего в качестве таких результатов обозначаются достижения обучаемых и приобретенные ими компетенции [1], а также степень трудоустраиваемости выпускников [2]. Второй подход - маркетинговый [3] - направлен на оценку соответствия выпускаемых специалистов и их отдельных характеристик потребностям рынка труда и запросам общества. Третий подход - процессный - ориентирован на оценку качества образования через процессы на разных этапах [4]. Он предполагает построение системы «вход - выход» и установление заданных параметров образования. Четвертый подход - комплексный - сочетает в себе оценку процессов и результатов образования [5]. В исследованиях зарубежных авторов качество 
образования также представляет собой «комплексный концепт» [6]. Данный подход компенсирует возможные недостатки остальных методик.

Материалы и методы. Методами изучения выступили вторичный анализ результатов социологических исследований, проведенных в разные годы (2009-2016 гг.) в организациях системы СПО, а также дискурс-анализ текстов отчетов о результатах этих опросов. Критерием отбора организаций послужила доступность данных (отчетов, размещенных в открытом доступе). Проанализированы материалы нескольких исследований. В организациях СПО Тамбовской области в 2009 г. проанкетированы обучаемые $(N=537)$, их родители $(N=712)$, руководители предприятий, с которыми учреждения начального и среднего профессионального образования заключили договоры о взаимодействии ( $\mathrm{N}=217)$ [7]. В Тамбове и Тамбовской области в 2015 г. опрошены руководители организаций $(\mathrm{N}=284)$, обучающиеся выпускных курсов $(\mathrm{N}=818)$, их родители ( $\mathrm{N}=872)$ [8]. В Центре социологических и маркетинговых исследований Гуманитарного университета осуществлен мониторинг качества образования организаций СПО, подведомственных Министерству культуры и туризма Свердловской области [9]. Обследовано 7 колледжей $(\mathrm{N}=$ 833). В анкетировании по поводу качества СПО в Санкт-Петербурге приняли участие руководители предприятий и организаций города, принимающие на работу выпускников образовательных организаций СПО (2013-2015 гг., N = 600, многоступенчатая выборка) [10]. При мониторинге Кузбасского регионального института развития профессионального образования (ежегодном социологическом опросе, проводимом методом анкетирования «Удовлетворенность обучающихся и их родителей (законных представителей) качеством образовательных услуе») в 2016 г. обследовано 65 профессиональных образовательных организаций (ПОО) Кемеровской области, что составило $100 \%$ ПОО области [11]. В Российском государственном профессионально-педагогическом университете (РГППУ) в качестве экспертов были опрошены руководители СПО, преподаватели-методисты, представляющие 85 субъектов РФ (N = 485) [12].

Основные результаты исследования. Итоги опросов показали, что мониторинг качества СПО становится все более распространенным инструментом оценки качества образования. Методами мониторинга чаще всего выступают опросы, анализ результатов учебной деятельности, тестирование обучаемых. Фиксируется средний балл по результатам тестов, что дает основание определить наличие или отсутствие позитивных/негативных изменений в успеваемости. Подобный мониторинг с опорой на тестирование используется, например, в организациях Тамбовской области. Отрицательная динамика изменений нацеливает руководителей организации и преподавателей на дополнительную диагностику ее причин с помощью опроса обучаемых и преподавателей [13].

В исследованиях качества СПО по организациям Кемеровской, Свердловской, Тамбовской областей во главу угла ставилась удовлетворенность потребителей (обучаемых и их родителей) качеством образовательных услуг. Подавляющее большинство респондентов отметили, что им нравится та организация СПО, где они (их дети) обучаются. Так, в организациях Тамбовской области эта доля респондентов составила $90 \%$ среди самих обучаемых и $96 \%$ среди их родителей в 2009 г.; 99 \% среди обучаемых и столько же среди родителей в 2015 г.

При этом само понятие «качество образования» родители обучаемых понимают как «обеспечение достаточной подготовки для работы по полученной специальности (профрессии)» [14]. Соответственно, исследуется вопрос о том, в какой мере та или иная образовательная организация отвечает данной цели. В организациях Тамбовской области такой вопрос был задан обучаемым: «Считаешь ли ты, что знаний, полученных в учебном заведении, достаточно для осуществления трудовой деятельности по выбранной специальности?» В результате 87 \% респондентов ответили положительно. Вместе с тем проблематично установить, насколько валидны полученные ответы, ведь по сути вопрос не операционализирован и имел вольную трактовку среди обучаемых. Схожие результаты получены в исследовании организаций СПО по Кемеровской области (85 \% обучаемых и 87 \% их родителей ответили, что полностью удовлетворены качеством образования) [15]. В опросах по Свердловской области респонденты-обучаемые выразили общую удовлетворенность организацией учебного процесса (32 \% полностью удовлетворены, 43 \% удовлетворены частично); на наш взгляд, здесь присутствует та же ошибка - вопрос не операционализирован [16].

Анализ показал, что организации СПО все в большей степени стремятся проводить всестороннюю оценку качества образования, привлекая к участию в исследованиях обучаемых, их родителей, преподавателей и работодателей. Так, встречный вопрос, заданный работодателям в Тамбовской области: «Удовлетворены ли Вы качеством образования выпускников среднего профрессионального образования?», вызвал следующее распределение ответов: полностью удовлетворены лишь 20 \% работодателей, удовлетворены частично - $44 \%$. Это позволяет сделать вывод о слабой обратной связи организаций СПО с работодателями, поскольку потребности последних недостаточно учтены. 
Авторы исследования СПО делали попытку детализировать качество образования на отдельные составляющие, включая кадровое обеспечение, педагогические и образовательные условия, воспитательную и культурно-досуговую деятельность, бытовые условия обучения и пребывания в учебной организации и т. д. Результаты опросов показывают, что обучаемые и их родители среди выделенных компонентов на первое по значимости место ставят профессионализм преподавателей и мастеров производственного обучения (например, в анкетировании по Тамбовской области в 2009 г. доля респондентов-родителей, удовлетворенных данным параметром, составила 64 \%, респондентов-обучаемых - 62 \%). В 2015 г. доля обучаемых, удовлетворенных этим аспектом, составила $77 \%$.

Вместе с тем следует отметить некорректную постановку проблемы о доминирующих факторах качества СПО: вопрос о наиболее важных компонентах качества образования фрактически интерпретирован как вопрос об оценке данных компонентов в условиях конкретной учебной организации. В схожих исследованиях по Свердловской области этот вопрос был поставлен более корректно, в результате среди обучаемых доля респондентов, удовлетворенных качеством преподавания, составила 37 \% (кроме того, 43 \% удовлетворены частично) [17]. В изучении качества СПО по Кемеровской области высчитывали индекс удовлетворенности потребителей образовательных услуг, он представляет собой интегральное значение по ряду ключевых показателей СПО [18]. Результаты показали, что максимально высоко оценен уровень профессионализма преподавателей (индекс удовлетворенности составил 87 \% для обучаемых и 90 \% для их родителей).

В свете оценки данного параметра образования в исследовании Российского государственного профессионально-педагогического университета подробно анализировали компетентностный срез кадрового состава системы СПО [19]. Результаты показали, что у преподавателей недостаточно развиты отдельные группы компетенций, что, безусловно, негативно влияет на качество преподавательской деятельности. Так, у 74 \% слабо развита межкультурная компетенция, у 54 \% не развита компетенция «управление проектами, педагогическое проектирование», в том числе формирование индивидуальных траекторий. Кроме того, у преподавателей системы СПО слабо развит уровень владения современными технологиями обучения (проектным, модульным обучением и т. д.).

В исследованиях по Свердловской области респонденты-обучаемые выразили озабоченность таким параметром качества СПО, как организация производственной практики (только 32 \% полностью удовлетворены, 36 \% удовлетворены частично). Менее всего обучаемые довольны техническим оснащением и оборудованием учебных аудиторий - общая удовлетворенность ниже 50 \%. Преподаватели отметили наибольшие сложности в организации производственной практики обучаемых, а также технической обеспеченности учебного процесса: «Серьезная проблема - это отсутствие нового инструментария. Парк роялей изношен более чем на 90 \%» (руководитель Свердловского музыкального училища).

По Кемеровской области фиксируются схожие результаты: наиболее низко оценен такой параметр качества СПО, как техническая обеспеченность учебного процесса. Исследование работодателей по Тамбову и Тамбовской области 2015 г. показало, что организация производственной практики как фактор качества СПО по-прежнему неудовлетворительна, поскольку часть работодателей фиксирует отсутствие заинтересованности в таком сотрудничестве, хотя положительная динамика в сравнении с данными за прошлые годы все же намечается. Замечания со стороны родителей обучающихся получили и такие параметры оценки качества СПО, как материально-техническая оснащенность образовательной организации. Доля подобных нареканий по сравнению с отмечаемыми в более ранние года возросла [20].

Качество образования работодатели оценивали прежде всего с позиции соответствия результатов обучения конкретным требованиям, предъявляемым к выпускникам. В числе обязательных работодатели называют профильное образование (например, в исследовании по Тамбовской области 2009 г. их доля составила 80 \%), опыт работы (соответственно 47 \%), состояние здоровья и возраст. По результатам исследований в Тамбове и Тамбовской области 2015 г. базовыми требованиями к выпускникам организаций СПО помимо собственно диплома об СПО выступают обязательное прохождение производственной практики на конкретном предприятии (34 \%), опыт работы (34 \%). При этом фактически полностью удовлетворена уровнем подготовки выпускников лишь половина работодателей.

В исследовании работодателей по Санкт-Петербургу получены следующие результаты: качество теоретической подготовки выпускников оценено респондентами-работодателями как удовлетворительное в 63 \% ответов, качество практических навыков - в 48 \%. Примечательно, что почти треть (31 \%) работодателей выразили неудовлетворенность навыками практической подготовки выпускников образовательных организаций СПО [21]. 
К дополнительным требованиям работодатели относят социальные навыки, личностные качества, дополнительные умения. Например, исследование по Санкт-Петербургу показало, что такое качество, как личная ответственность за выполнение производственных задач, у выпускников системы СПО, по оценкам работодателей, развито невысоко: 5 баллов по 5-балльной шкале им присвоили 14 \% работодателей, $4-40,1$ и 2 - 7 \%. Также недостаточно развитой у выпускников является компетенция «готовность к саморазвитию и повышению квалификации»: 8 \% работодателей выразили неудовлетворенность состоянием данной компетенции, большинство респондентов (40 \%) оценили ее на 3 балла. Оценка в 3 и 4 балла поставлена респондентами за развитие коммуникативных и информационных компетенций выпускников.

Выводы и заключения. Анализ результатов исследований в области оценки качества СПО показал, что сегодня данными вопросами занимаются все больше организаций системы СПО. Положительной тенденцией становится обращение к всесторонней оценке качества СПО, включающей мнения разных субъектов образования - обучаемых, их родителей, менеджеров (руководителей) и педагогических работников, а также работодателей.

Дискурс-анализ текстов отчетов выявил доминирующий подход в оценке качества СПО маркетинговый, где главным критерием качества является удовлетворенность потребителя образовательных услуг. Данная категория становится центральной. Слабо используется комплексная методика как сочетание результатного, маркетингового и процессного подходов. Это позволяет заключить, что анализ, базирующийся только на опросах потребителей, не является глубоким, поскольку игнорируются или не учитываются другие стороны и методы оценки.

Дискурс-анализ показал, что комплексное понятие «образование» практически во всех проанализированных источниках ошибочно сводится к образовательным услугам.

Выявлены случаи недостаточной операционализации инструментария, что обусловливает искажение результатов. Например, оценка такого синтетического и слабо операционализированного понятия, как «качество образования», приводит к завышенным цифрам удовлетворенности им, в то время как детализация данной категории выявляет обратную картину. В связи с этим наиболее проблемными звеньями выступают такие параметры образования, как техническая оснащенность учебного процесса, организация производственной практики, кадровое обеспечение.

Из исследования становится также очевидно, что налицо несоответствие интересов потребителей образовательных услуг. Фактически можно говорить и о слабой обратной связи работодателей с образовательными организациями системы СПО, поскольку их потребности недостаточно системно выявляются и учитываются при подготовке соответствующих специалистов. Функция социологической диагностики - не только выявление проблемных звеньев, но и их оптимизация. Таким образом, анализ показал, что важнейшим направлением в развитии управления качеством СПО на данном этапе является совершенствование методики социологической оценки, выстроенной на методологической основе комплексного подхода.

\section{Ссылки и примечания:}

1. Бобров В.В. Образование: «качество» и «инновации» // Философия образования. 2009. № 3. С. 40-48 ; Ковлякова В.Е. Оценка качества среднего профессионального образования в рамках государственного контроля : дис. ... канд. пед. наук. М., 2013. 209 с.

2. Белый В.М. Некоторые аспекты повышения качества образования // Alma mater. 2013. № 6. С. 68-72.

3. Александров А.Е., Лисов В.И. Новый этап развития начального и среднего профессионального образования г. Москвы. М., 2004. 36 с. ; Белоцерковский А.В. О «качестве» и «количестве» образования // Высшее образование в России. 2011. № 4. С. 3-11; Богачева Е.С. Среднее профессиональное образование : авторефр. дис. ... канд. социол. наук. Новочеркасск, 2011. 19 с. ; Казеев А.Ф. Социально-профессиональное становление студентов многопрофильного колледжа : автореф. дис. ... канд. пед. наук. Казань, 2005. 18 с. ; Стребкова Н.В. Социологический аспект проблемы оценки качества образования // Вестник Поволжского института управления. 2008. № 2. С. 171-180.

4. Ковальчук О.В. Повышение эфффективности образовательных систем на основе разработки муниципальной системы управления качеством образования // Экономические и гуманитарные исследования регионов. 2012. № 1. С. 28-36 ; Проценко Т.Н. Процессный подход к созданию системы управления качеством образования в колледже // Среднее профессиональное образование. 2007. № 1. С. 2-3.

5. Субетто А.И. Государственная политика качества высшего образования: концепция, механизмы, перспективы [Электронный ресурc]. URL: http://www.trinitas.ru/rus/doc/0012/001a/00120196.htm (дата обращения: 10.04.2018).

6. Godfrey T. How Should Quality of Education Be Re-Defined for Education Achievements in Tanzania? What Are Stakeholders' Opinions? // Journal of International Education and Leadership. 2013. Vol. 3, iss. 1. P. 1-7.

7. Мониторинг качества обучения студентов как средство управления образованием [Электронный pecypc]. URL: http://открытыйурок.рф/статьи/214517/ (дата обращения: 10.04.2018).

8. Результаты социологического исследования удовлетворенности качеством среднего профессионального образования [Электронный ресурс] / авт.-сост. М.Ю. Лимонова. Тамбов, 2015. 32 c. URL: http://ipk.68edu.ru/images/stories/2015/deyatelnost/monitoring/broshiura-kach-prof-obr.pdf (дата обращения: 10.04.2018).

9. Шуклина Е.А. Исследование Центра социологических и маркетинговых исследований Гуманитарного университета [Электронный ресурc]. URL: http://mkso.ru/data/File/itogovii\%20otchet\%20spo.pdf (дата обращения: 10.04.2018).

10. Социологический мониторинг качества среднего профессионального образования в Санкт-Петербурге / под ред. Р.А. Костина, Е.В. Шишкиной. СПб., 2016. 171 с. 
11. Мониторинг деятельности ПОО. Социологические исследования [Электронный ресурc]. URL: http://www.krirpo.ru/activity-2/monitoring/sotsiologicheskie-issledovaniya (дата обращения: 10.04.2018).

12. Отчет о научно-исследовательской работе Российского государственного профессионально-педагогического университета [Электронный ресурc]. URL: http://monitoring.rsvpu.ru (дата обращения: 10.04.2018).

13. Мониторинг качества ...

14. Здесь и далее в тексте курсивом и в кавычках приводятся оригинальные формулировки ответов респондентов.

15. Мониторинг деятельности ...

16. Исследование ...

17. Там же.

18. Мониторинг деятельности ...

19. Отчет ...

20. Результаты ...

21. Социологический мониторинг ...

\section{References:}

Aleksandrov, AE \& Lisov, VI 2004, A new stage in the development of primary and secondary vocational education in Moscow, Moscow, 36 p., (in Russian).

Belotserkovsky, AV 2011, 'Concerning the quality and quantity of education', Vyssheye obrazovaniye v Rossii, no. 4, pp. 311, (in Russian).

Belyy, VM 2013, 'Several aspects of improving the quality of education', Alma mater, no. 6, pp. 68-72, (in Russian).

Bobrov, VV 2009, 'Education: quality and innovation', Filosofiya obrazovaniya, no. 3, pp. 40-48, (in Russian).

Bogacheva, ES 2011, Secondary vocational education, PhD thesis abstract, Novocherkassk, 19 p., (in Russian).

Godfrey, T 2013, 'How Should Quality of Education Be Re-Defined for Education Achievements in Tanzania? What Are Stakeholders' Opinions?', Journal of International Education and Leadership, vol. 3, iss. 1, pp. 1-7.

Kazeev, AF 2005, Social professional development of students of a multidisciplinary college, PhD thesis abstract, Kazan, 18 p., (in Russian).

Kostina, RA \& Shishkina, EV (eds.) 2016, Sociological monitoring of the quality of secondary vocational education in St. Petersburg, St. Petersburg, 171 p., (in Russian).

Kovalchuk, OV 2012, 'Increasing the efficiency of educational systems based on the development of the municipal management system related to the education quality', Ekonomicheskiye i gumanitarnyye issledovaniya regionov, no. 1, pp. 28-36, (in Russian).

Kovlyakova, VE 2013, Evaluation of the quality of secondary vocational education under the state control, PhD thesis, Moscow, 209 p., (in Russian).

Limonova, MYu (ed.) (comp.) 2015, The results of a sociological study on satisfaction with the quality of secondary vocational education, Tambov, 32 p., viewed 10 April 2018, <http://ipk.68edu.ru/images/stories/2015/deyatelnost/monitoring/broshiura-kachprof-obr.pdf>, (in Russian).

Protsenko, TN 2007, 'Process-based approach to creating the education quality management system at college', Sredneye professional'noye obrazovaniye, no. 1, pp. 2-3, (in Russian).

Shuklina, EA 2018, A survey of the Center for Sociological and Marketing Research of the Humanities University, viewed 10 April 2018, <http://mkso.ru/data/File/itogovii\%20otchet\%20spo.pdf>, (in Russian).

Strebkova, NV 2008, 'Sociological aspect of assessing the quality of education', Vestnik Povolzhskogo instituta upravleniya, no. 2, pp. 171-180, (in Russian).

Subetto, Al 2018, State policy on higher education quality: concept, mechanisms, prospects, viewed 10 April 2018, <http://www.trinitas.ru/rus/doc/0012/001a/00120196.htm>, (in Russian). 